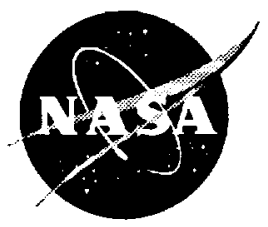

\title{
Multi-Axis Thrust Measurements of the EO-1 Pulsed Plasma Thruster
}

Lynn A. Arrington

Dynacs Engineering Company, Inc., Brook Park, Ohio

Thomas W. Haag

Glenn Research Center, Cleveland, Ohio

Prepared for the

35th Joint Propulsion Conference and Exhibit cosponsored by AIAA, ASME, SAE, and ASEE

Los Angeles, California, June 20-24, 1999

National Aeronautics and

Space Administration

Glenn Research Center 
Trade names or manufacturers' names are used in this report for identification only. This usage does not constitute an official endorsement, either expressed or implied, by the National Aeronautics and Space Administration.

NASA Center for Aerospace Information 7121 Standard Drive

Hanover, MD 21076

Price Code: A03
National Technical Information Service 5285 Port Royal Road Springfield, VA 22100

Price Code: A03 


\title{
MULTI-AXIS THRUST MEASUREMENTS OF THE EO-1 PULSED PLASMA THRUSTER
}

\author{
Lynn A. Arrington \\ Dynacs Engineering Company, Inc. \\ NASA John H. Glenn Research Center \\ Cleveland, $\mathrm{OH} 44135$ \\ Thomas W. Haag \\ NASA John H. Glenn Research Center \\ Cleveland, $\mathrm{OH} 44135$
}

\begin{abstract}
Pulsed plasma thrusters are low thrust propulsive devices which have a high specific impulse at low power. A pulsed plasma thruster is currently scheduled to fly as an experiment on NASA's Earth Observing- 1 satellite mission. The pulsed plasma thruster will be used to replace one of the reaction wheels. As part of the qualification testing of the thruster it is necessary to determine the nominal thrust as a function of charge energy. These data will be used to determine control algorithms. Testing was first completed on a breadboard pulsed plasma thruster to determine nominal or primary axis thrust and associated propellant mass consumption as a function of energy and then later to determine if any significant off-axis thrust component existed. On conclusion that there was a significant offaxis thrust component with the breadboard in the direction of the anode electrode, the test matrix was expanded on the flight hardware to include thrust measurements along all three orthogonal axes. Similar. off-axis components were found with the flight unit.
\end{abstract}

\section{Introduction}

Recent advances in electronic technology and the movement to smaller satellites has renewed interest in the use of pulsed plasma thrusters (PPT) for small satellite missions. As low thrust electric devices, PPTs operate at high specific impulse across a broad power range (5-200W). Potential uses for PPTs range from attitude adjustment to precision positioning to orbit raising.

A PPT is generally an ablative device that uses a fluorocarbon polymer as propellant. A solid bar of propellant is fed between a pair of electrodes that are connected to opposing poles of a high voltage capacitor. A spring forces the fuel bar against shoulders located in the electrode faces. The shoulders hold the fuel bar a fixed distance from the electrode ends. A spark plug is located in the cathode electrode face in close proximity to the fuel bar face. The spark plug is generally two concentric electrodes with a ceramic insulator between the pair. As a pulsed device, the high voltage capacitor is charged within hundreds of milliseconds to a potential discharge energy of 5-55 Joules. By activating the spark plug with energy on the order of tenths of joules, a few electrons are released which allows discharge of the main capacitor in 5-10 microseconds. This discharge ablates the surface of the propellant, ionizes it, and accelerates it via self-induced electromagnetic forces.

In 1995 in order to address future NASA requirements for propellant efficient, small impulse-bit propulsion, NASA Glenn Research Center (GRC) initiated a technology program in pulsed plasma thrusters. The technology was viewed as enabling for multi-spacecraft formation flying, such as envisioned for next generation deep space imagers. The initial goals were to identify improvernents in technologies over the past two decades which could be injected into the 1970's vintage TIP/NOVA ${ }^{1}$ and LES $8 / 9^{2}$ designs, and to reestablish an industrial base for the thrusters. Successive goals seek to dramatically improve thruster efficiency which will open the potential for application to orbit-raising of LEO microsatellites, and to dramatically reduce thruster size while lowering cost. Under the first phase of the program, NASA assembled a substantial Pulsed Plasma Thruster development infrastructure as part of the Glenn Research Center Electric Propulsion Testbed. It includes facilities for PPT development testing with micronewton-class thrust measurement capability, multimillion pulse capacitor life test facilities, plume contamination assessment chambers, and PPT plume electromagnetic emission measurement facilities. Primex Aerospace Co. was selected as the first industrial partner and was tasked to initially build a breadboard engine using selected new technologies and heritage designs from earlier PPT programs, and then tasked to design and build a protoflight thruster. NASA's New Millenium Program, which is designed to rapidly demonstrate new space technologies, selected the PPT to fly on its first Earth Observing-1 satellite (EO-1) managed by the Goddard Space Flight Center and built by Swales Aerospace. 
The EO-1 mission is an earth observing satellite on which a PPT will be operated as an experiment to replace the pitch axis reaction wheel late in the mission. As part of this program, Primex first built, then completed functional and preliminary performance testing of a breadboard (BB) PPT $^{3}$ Extensive performance testing followed at GRC where different electrode configurations were tested to determine the most appropriate configuration for this application. ${ }^{4}$ Data and lessons learned from building and testing of the breadboard were then used as the basis for the design and construction of a protoflight unit.

During development, a concern arose that while performance measurements along the primary axis were well quantified, it was not known if there were off-axis components of the thrust. This could adversely affect the satellite by applying unforeseen torques and forces. Prior to testing of the flight hardware, thrust measurements were conducted individually along all three axes on the breadboard PPT to determine if the off-axis components were significant. As a result of these data, similar tests were performed on the flight hardware. After some initial verification tests at Primex, the PPT was sent to GRC where it underwent acceptance testing. As part of the acceptance test program, performance tests were performed to generate data needed to determine algorithms necessary for the satellite control programming. Thrust and impulse bit measurements were performed along three orthogonal axes for each electrode pair of the PPT.

There were physical differences between flight and breadboard PPTs that made independent performance measurements on both units necessary. The following points highlight the breadboard-to-flight unit differences that could affect off-axis thrust.

- Main capacitor position

- Electrode distance from capacitor

- Stripline configuration

- Horns or plume directors

The mechanical differences are explained more fully under the PPT descriptions. Also, there could be differences in the primary thrust and impulse bit due to differences in the power processing units.

In general, it was shown in a previous study ${ }^{2}$ that on a pulse-to-pulse basis there are random variations in impulse bit related to the location of the spark around the plug circumference relative to the fuel face. This also impacted mass consumption per pulse, specific impulse and thruster efficiency. The impulse bit data was found to increase as much as $20 \%$ beyond the minimum recorded value and the specific impulse data $35 \%$ beyond the minimum value. Performance tests for that study, were conducted on a PPT with a semiconductor plug installed in the cathode electrode. The plug face was milled down except at one Iocation to force the arc at that point, then the plug was rotated within the cathode electrode. Mass loss measurements and impulse bit measurements were made at each location, which showed both were highest when the spark was closest to the fuel face.

Performance measurements, for this study, were conducted on a thrust stand developed at NASA GRC. ${ }^{5}$ The thrust stand was designed to be sensitive only along one axis, and ignore all force components perpendicular to that axis. The thrust stand was used previously to measure thrust and impulse bit along the axis normal to the face of the fuel bars or in the direction of the main body of the plume. To simplify the discussions in this paper, a coordinate system was arbitrarily chosen that is generic to any electrode pair. With the origin at the center of the fuel bar face the axis normal to surface in the direction of plume travel was referred to as the $+z$ axis as shown in Figure 1. The direction toward the anode was referred to as the $+x$-axis and the $+y$-axis falls according to the right hand rule. The breadboard PPT electrodes were configured to match the protoflight hardware and both PPTs were tested for thrust and impulse bit along the primary thrust axis $Z$. Both were then mounted so that the off-axis thrust could be measured independently in the $x$ and $y$ directions. Different capacitor energy levels were investigated. As seen in the older study and the data generated for this study, there was a variation in measured impulse bit from pulse to pulse. The average impulse bit was generally calculated from a small number of pulses due to time constraints. A statistical distribution of impulse bit for these PPTs and this thrust stand had not been performed, so an additional test with the BB PPT was conducted where a large number of impulse bit pulses were taken at a single energy level to determine the pulse to pulse distribution.

\section{Test Hardware}

\section{$\underline{\text { BB PPT }}$}

The BB PPT was built by Primex Aerospace as part of a GRC development effort. The PPT was designed with interchangeable components, so that the PPT configuration could be modified with ease. This allowed variation of such components as electrode length, separation distance, and flare. The impact of configuration changes on performance were examined in a previous study. ${ }^{4}$ For the tests reported in this study, the BB PPT was configured to match the flight hardware design, and the main capacitor was changed to 
an engineering model of the flight capacitor. As seen in the Figure 2, the BB PPT has two electrode pairs with the primary z-axis in the same direction as the centerline of the main capacitor, but neither pair has a horn extension.

\section{EO-1 PPT}

A detailed overview description of the flight hardware, which is pictured in Figure 3, is available in Reference 6. As seen in the figure, the PPT has two opposing electrode pairs and the normal axis of the thrusters is perpendicular to the centerline of the main capacitor. The two opposing pairs are indicated as side 1 and side 2 as shown in the figure. The flight hardware has diverging horns with a $20^{\circ}$ flare to contain the near field plume. The EO-1 PPT has the same electrode spacing, electrode length and flare as the BB PPT. Also, the same model of semiconductor spark plug is used in both units.

\section{Test Description}

\section{$\underline{\text { Test Apparatus }}$}

The thrust stand was installed in a high vacuum facility where tank pressures were typically $10^{-6}$ torr. The facility is a $1.5 \mathrm{~m}$ diameter, $4.5 \mathrm{~m}$ long stainless steel tank, held at vacuum by four oil diffusion pumps. The PPT was operated in both continuous mode, meaning the PPT fired automatically at $1 \mathrm{~Hz}$, and single pulse mode, meaning the PPT fired only once. Continuous mode is used to determine the effective average thrust, $T$, and single pulse mode to determine the impulse bit, $I_{b}$. Prior to and following each axis data set, the thrust stand was calibrated to determine both the spring constant and the natural frequency of the thrust stand. The thrust stand utilizes a horizontal swing arm with the PPT mounted on the end of the arm. As the PPT fires horizontally, the tangential force causes the arm to rotate, and a linear variable differential transformer (LVDT) measures the deflection of the arm. A restoring spring eventually returns the arm to its neutral position. In continuous mode, the PPT is fired repeatedly at a rate several times the natural frequency of the thrust stand. As a result, impulse bits are averaged over time and the thrust stand responds as if a smooth continuous force were being applied. The PPT deflects to an equilibrium position, held there by the opposing restoring force and PPT thrust. When firing stops the arm returns to its neutral position. For a single pulse, the damper on the arm is deactivated and a single pulse fired, causing the arm to oscillate back and forth about its neutral position at the thrust stand natural frequency. The deflection amplitude of the thrust stand is then used to calculate the impulse bit. After a few oscillations the damper is restored and the PPT returns to its neutral position. The thrust stand can only measure displacement along one axis at time, so the PPT has to be repositioned accordingly on the stand to measure each axis.

\section{$\underline{B B}$ PPT}

Testing conducted with the BB PPT was only completed with one set of electrodes as the other pair was configured differently. The BB PPT was mounted in the tank so that the $z$-axis was measured parallel to the long axis of the vacuum facility to limit wall interactions. This required the entire thrust stand be repositioned in the tank when switching from $\mathrm{z}$-axis to off-axis $x$ and $y$ components of thrust. By mounting the PPT in three different orientations, the primary $z$ thrust component as shown in Figure 4, and the two off-axis components were measured directly. Each component was measured at four capacitor energy levels, 54, 43, 32 , and $21 \mathrm{~J}$. Following testing at each energy level for the primary axis measurements only, the tank was opened to atmosphere. That allowed the fuel bar to be removed and the mass loss at each energy level weighed. These data were then used for specific impulse calculations, that in turn could be used to make approximations of the specific impulse of the EO-1 hardware. The fuel bar could not be removed from the protoflight EO-1 hardware to make similar calculations. The test sequence for each capacitor energy level in the primary thrust direction was:

1) Four - 5 minute continuous runs at $1 \mathrm{~Hz}$

2) 25 single pulses

3) Four -5 minute continuous runs at $1 \mathrm{~Hz}$

4) 25 single pulses

5) Four -5 minute continuous runs at $1 \mathrm{~Hz}$

6) 25 single pulses.

The test sequence was long enough to obtain a measurable mass loss. The off-axis thrust test sequences, which required no mass loss data, were:

1) Three -3 minute continuous runs at $1 \mathrm{~Hz}$

2) 20 single pulses

3) Three -3 minute continuous runs at $1 \mathrm{~Hz}$

at each energy level.

An additional test was performed in an effort to isolate the effect of the z-axis thrust on the thrust stand during off-axis component measurements. The thrust stand was installed in the primary thrust configuration, but the PPT z-axis was pointed straight up so the only 
measurements were the $\mathrm{x}$ - and $\mathrm{y}$-axis components in the horizontal. The pivot axis of the thrust stand and the $z$ axis of the PPT were parallel within $0.2^{\circ}$ of each other. First the $x$-axis component was tested, followed by the $y$-axis. The same test sequence was used as for the previous off-axis tests except 30 individual pulses were recorded.

Time constraints made it infeasible to obtain a statistically viable impulse bit data set at every energy level and axis orientation of the PPT, so a single test along the primary axis at one energy level was conducted. Data were taken over 700 individual pulses at the $54 \mathrm{~J}$ energy level. The data were collected over three separate days. The tank remained at vacuum throughout the course of testing.

\section{EO-1 PPT}

The EO-1 PPT hardware was initially tested over a 6 day period where one axis of each side of the thruster was fired per day. Again, each position required that the fired electrode pair be aimed down the long axis of the tank, to minimize tank wall interaction and protect the thrust stand calibration weights. The primary or $z$ axis setup is shown in Figure 5. For z-axis data when switching from side 1 to side 2 , the PPT was horizontally rotated $180^{\circ}$ on the thrust stand arm. To obtain the off-axis data, the thrust stand was horizontally rotated $90^{\circ}$ within the tank changing the direction of motion for the thrust stand arm, but the PPT was positioned to still maintain the $\mathrm{z}$-axis firing down the long tank axis. To measure data along the $x$-axis, the PPT was laid flat on the arm shown in Figure 6, so the $x-z$ plane was horizontal. Then the PPT was turned as shown in Figure 7 to measure data along the $y$-axis, so the $y-z$ plane was horizontal.

For each position, five different main capacitor energy levels were tested. Each energy level corresponds to the length of time required by the power processing unit to charge up the main capacitor to that level. In this case, the maximum and minimum charge durations and three intermediate durations were tested: $920,720,520$, 320 , and $120 \mathrm{~ms}$ corresponding to estimated energy levels of $55.8,43.2,30.1,18.7$, and $6.4 \mathrm{~J}$ respectively. The test sequence for each charge duration, was as follows:

1) three 3-minute continuous runs at $1 \mathrm{~Hz}$

2) 10 single pulses

3) three 3-minute continuous pulse at $1 \mathrm{~Hz}$

4) 10 single pulses.
The different energy levels were tested to measure the thrust and impulse bit as a function of charge duration over the range of possible PPT operation.

These tests were taken prior to infant mortality test as required under the acceptance test plan. Following the life test performed on each side of the PPT, further performance measurements were conducted on the primary z-axis of each side. The concern was that the performance may have changed since the original six tests were conducted on a virtually "new" thruster and as the life test had "aged" each electrode pair by 100,000 pulses.

\section{Results and Discussion}

Typical thrust stand responses are shown in Figures 8 and 9 for continuous and single pulse data, respectively. This set was collected for a $720 \mathrm{msec}$ charge duration run with the EO-1 PPT. The data depicted in Figure 8 were chosen as a representative case to show the fluctuation in displacement with time, which was directly related to the variation in thrust. The data were used to calculate an averaged thrust. As seen in the figure, the thrust stand trace started in a neutral position until the PPT began to fire continuously. Then the thrust stand deflected and reached an equilibrium position, where the PPT thrust and restoring force were in balance. When the PPT operation ceased the thrust stand returned to its neutral position. Likewise in Figure 9, the amplitude of each pulse train was used to directly calculate the impulse bit for each individual pulse, then an averaged impulse bit was calculated from the data set. As seen in the figure, the thrust stand again started from a neutral position. A single pulse was fired from the PPT and the thrust stand was allowed to oscillate about the neutral position twice before damping was restored, resulting in the decreasing amplitude of succeeding oscillations until the thrust stand returned to the neutral position. The figure shows a total of five individual pulses.

\section{BB PPT}

Figure 10 illustrates the direction of the plume components that were found, and their relationship to the BB PPT axes. The corresponding thrust vectors are in the opposite directions. The $\mathrm{z}$-axis thrust vector is normal to the fuel bar surface between the active cathode and anode electrodes. Table 1 provides the test data for average thrust and impulse bit along the $z-, x-$ and y-axes. For example at the 54 joules capacitor energy level, the thrust along $\mathrm{z}, \mathrm{y}$, and $\mathrm{x}$-axes are 890 , 19 , and $67 \mu \mathrm{N}$, respectively. Given that the all testing was conducted at $1 \mathrm{~Hz}$, and thrust can be calculated 
from the impulse bit multiplied by the frequency, there was very good consistency between the impulse bit and measured thrust. The test indicated that the total thrust vector is not parallel to the $\mathrm{z}$-axis, which is referenced to the electrodes/BB PPT mechanical axes. In Table 2, the average divergence angle is calculated relative to the $x$ and $y$ off-axis BB PPT positions. Using the example presented above, this resulted in divergence angles of 1.2 and $4.3^{\circ}$ with the $y$ and $x$-axes, respectively. Potentially some of this off-axis thrust could be due to a small misalignment between the PPT and thrust stand. From the mass loss measurements and other data, the specific impulse for each energy level are calculated as: $1360 \mathrm{sec}$ at $54 \mathrm{~J}, 1200 \mathrm{sec}$ at $43 \mathrm{~J}, 1022$ sec at $32 \mathrm{~J}$ and $843 \mathrm{sec}$ at $21 \mathrm{~J}$.

In Table 3 the calculated uncertainties and the potential variances are listed. Uncertainties were calculated using standard propagation techniques. For thrust uncertainty, contributions considered included: pre- and post-test calibration weights, the thrust stand deflection during calibration, and averaging the thrust stand deflection under continuous pulsing. For impulse bit uncertainty, the contributions considered included: preand post-test calibration weights, the thrust stand deflection during calibration, the measured deflection during a single pulse, and pulse count and time recorded during thrust stand natural frequency measurement. The measured response along the y-axis was less than the uncertainty and could be considered negligible. Meanwhile the measured response along the $x$-axis was greater than the uncertainty and the plume was biased towards the cathode electrode, resulting in the $\mathrm{x}$-axis component of the thrust vector being biased towards the anode electrode.

As mentioned previously, thrust is measured when the BB PPT is fired in continuous mode at $1 \mathrm{~Hz}$ while a damped spring force is applied. After a few pulses, the deflection of the thrust stand arm reaches an equilibrium position. The deflection of the PPT from its neutral to equilibrium position is used to calculate the thrust. However as the PPT fires, this deflection is not uniform but fluctuates with time. The thrust data presented in Table I are actually an "averaged" value for that deflection. In an effort to bound the actual variation of thrust, the maximum recorded single point deflection and minimum deflection were measured. Those values are subtracted from each other and divided by the average value found in Table 1, establishing a representative thrust variation, given in Table 3 . Similarly, the impulse bit data varies from shot to shot. The same technique was used to define that variation where the maximum and minimum impulse bits were subtracted and divided by the averaged impulse bit.
An alternate means of measuring the $x$ and $y$ components of the off-axis thrust was explored in an attempt to verify the previous results. Tests were therefore conducted with the BB PPT to isolate z-axis effects on thrust stand. The results are given in Table 4. The magnitudes along the $y$-axis were negligible and therefore, given the results from the earlier testing, leads to the conclusion that the $y$-axis thrust component was nearly zero or too small to measure accurately here. Results measured along the $\mathrm{x}$-axis were also greater than the uncertainties as seen in previous testing. The direction of the $\mathrm{x}$-axis thrust component was toward the anode electrode. These results, though slightly smaller, were on the same order of magnitude as those completed in the earlier test, leading to the conclusion that a PPT phenomena causes that component and not the thrust stand. The cause for that off-axis bias is unknown but may be caused by the dissimilarities in arc attachment on the cathode and anode surfaces.

Results of the test to determine a statistical distribution of impulse bit are shown in Figure 11. The 700 impulse bit measurements are grouped by percentage at increasing intervals of $15 \mu \mathrm{N}$-sec. As seen from the figure, the bar chart has a tendency towards a bell shape but with a mean being offset toward the lower values. The standard deviation was $23 \mu \mathrm{N}$-sec, with mean and median values of $947 \mu \mathrm{N}-\mathrm{sec}$, thus the standard deviation was about $2.5 \%$ of the mean value. As compared to the Table 3 data, the maximum impulse bit variation over the 700 pulses test was about $18 \%$ as compared to $11 \%$. The agreement between the mean and median values and small standard deviation over a significant number of pulses was promising, but the mean impulse bit was higher than the previous result recorded in Table 1 by $6.5 \%$. The uncertainty of this impulse bit measurement was calculated at less than $1 \%$ and the previous impulse bit measurement uncertainty was $5 \%$ at 54 Joules given in Table 3 . This result was higher than expected, so the thrust stand, thruster, and data acquisition equipment were checked to verify they were functioning correctly. A final z-axis performance test was conducted to verify the thrust and impulse bit at the four energy levels. Those results are given in Table 4. When compared to the results in Table I, at 54 and $43 \mathrm{~J}$, the second test was higher by $3-5 \%$ for both thrust and impulse bit. Those two energy levels also had the highest uncertainties during the first set of test. At the 32 and $21 \mathrm{~J}$ energy levels, the thrust and impulse bit were nearly identical between Tables 1 and 4 . The larger uncertainties in the original higher energy performance measurements could potentially explain in part why the average impulse bit from the 700 pulses test was higher than expected. However due to variation in PPT performance over even short periods 
of time, a larger statistical distribution could change the bias to one side on the distribution curve.

\section{EO-I PPT}

Numerical performance values are given in Tables 5-10. A verage thrust and impulse bit data for the primary axes are shown in Table 5. The same information is plotted in Figures 12 and 13. Off-axis components for the $x$ and $y$-axes are in Table 6 . As an example, the thrust magnitudes for side 1 at an estimated capacitor energy of 56 joules are 789,45 , and $4 \mu \mathrm{N}$ along the $z, x$, and $y$ axes respectively. Likewise for side 2 , the thrust magnitudes were 854,44 , and $11 \mu \mathrm{N}$ along the $z, x$, and $y$-axes respectively. A schematic of an end view of each electrode pair, Figure 14, gives the direction of the off-axis plume components relative to the fuel bar face. Vector angles defined by the primary axis and off-axis $x$ component are given in Table 7. For the above example, that results in angles of 3.3 and $2.9^{\circ}$ for sides 1 and 2 , respectively. The primary axis measurement uncertainties are given in Table 8. All data are recorded as a function of capacitor charge duration.

Results of the primary thrust axis testing, shown in Table 5, provide the following information: 1) side 2 performance was greater than side 1, and 2) generally there was good agreement between thrust and impulse bit at each energy level. The greater performance on side 2 was felt to be a function of the difference in the performance of the spark plugs themselves. The reference mentioned earlier showed that the spark breakdown location along the circumference of a single spark plug could result in a pulse to pulse variation by as much as $20 \%$ over the minimum recorded value. Therefore, two plugs are not likely to behave exactly the same. Table 9 illustrates the maximum variation in thrust and impulse bit for each PPT side and energy level. Side 2 thrust and impulse bit variability were comparable to the BB PPT, while side 1 variability was higher in several cases. A further illustration of the variation is seen in Figure 15, which shows the strip chart LDVT data for both sides 1 and 2 at $720 \mathrm{~ms}$ along the primary axes. Side 1 varies more with time than does side 2 , which is reflected by the table. In reference to the 700 pulse impulse bit test, the 3 -sigma variation in impulse bit was about $7 \%$ and significantly less than variation in impulse bit given in Table 3 at the same energy. Therefore, indicating that the 3 -sigma variation in impulse bit for the protoflight unit is likely smaller than the extremes given in Table 9. With all tests being conducted at a PPT frequency of $1 \mathrm{~Hz}$, the thrust magnitude and impulse bit should be the same. This was true within the measurement uncertainties, except for side one pre-life test run at $920 \mathrm{~ms}$ charge duration. The cause of this discrepancy is unknown.

The off-axis thrust data are summarized in Table 6 . For the data along the $\mathrm{x}$-axis, the plume biased towards the cathode electrode, as shown in Figure 14. Hence, the thrust vector was in the opposite direction towards the anode. For the tests at the lower charge durations, the deflections were too insignificant to measure so no values were recorded. The test data for these runs were indistinguishable from thrust stand operations without the PPT firing. The angles formed by the $\mathrm{z}$-axis and $\mathrm{x}$ axis data are given in Table 7, the worst cases were $5.3^{\circ}$ at $320 \mathrm{~ms}$ for side 1 and $3.6^{\circ}$ at $520 \mathrm{~ms}$ for side 2 . The thrust components measured for $\mathrm{x}$-axis were greater than the uncertainties calculated for the primary axis given in Table 8.

Y-axis thrust components were negligible except at the highest charge durations; even data obtained at $920 \mathrm{~ms}$ charge duration is less than the uncertainty for the thrust along the primary axis given in Table 8 . However, the measurements taken were biased to one side and the direction of the plume shown in Figure 14. Side 2 showed slightly larger off-axis components than side 1 , however a slight $0.2^{\circ}$ thrust axis mounting eпror was thought to contribute to this, which was later corrected when side 1 was mounted. Since the y-axis components were negligible, thrust angles relative to the $\mathrm{z}$-axis were not calculated.

Finally, data from two additional post-life performance tests conducted on the PPT are given in Table 10. The results indicated slightly lower performance at various energy levels, but the change was not consistent over a particular side. Side 2 still had a higher performance than side 1, the agreement between the impulse bit and thrust measurements was still good. As mentioned previously the difference in thruster performance is most likely related to the behavior of the spark plug, and after the wear of 100,000 pulses a contributor to the pre and post life test changes on each side. Data were not taken at $120 \mathrm{~ms}$ charge duration due to unreliable firing of the PPT on both sides. It has been noted in prior breadboard testing that the minimum spark plug breakdown voltage varies through the pulse life of the plug since the plug energy varies proportional to main capacitor energy. The lowest spark plug energy was not breaking down consistently, thus neither was the main capacitor. Tests conducted at $120 \mathrm{~ms}$ charge duration prior to the life test showed no firing abnormalities. ${ }^{5}$ 


\section{Conclusions}

Off-axis performance along the $y$-axis for both the BB and EO-1 PPTs have thrust and impulse bit magnitudes that are small in comparison to the uncertainties or too small to measure. Along the $\mathrm{x}$-axis the plume is definitely drawn towards the cathode electrode producing a measurable thrust component towards the anode electrode for both PPTs. The relative position of the capacitor with respect to the electrode pair did not seem to influence the thrust vector since the relative position of the capacitor axis to the electrode pairs is $90^{\circ}$ different between the two PPTs. Neither did the stripline configurations seem to cause this off-axis component. The component may be due to how the plume arcs across from one electrode face to the other, but it was not determined definitively here.

The performance data collected for the EO-1 hardware shows that side 2 outperforms side 1 along the primary axis. This result was consistent both before and after the life test was performed on each side. The average thrust and impulse bit are provided as a function of capacitor charge duration. For the off-axis measurements conducted prior to the life test, there is a thrust component in the direction of the anode electrode for both sides. For side 1 the angle formed by primary axis component and the off-axis component is less than $5.3^{\circ}$. For side 2 the angle is less than $3.6^{\circ}$. The magnitude of the off-axis thrust component that falls parallel with faces of the electrodes along the y-axis is less than the measurement uncertainty, so a similar angle was not calculated. The EO- 1 spacecraft attitude control is not significantly affected by the off-axis thrust component or impulse bit differences or variations of both PPT sides. Interface control requirements were modified to accommodate the measurements of these performance tests. The EO-1 software parameters will be developed using the actual protoflight thruster characteristics.

\section{References}

I Brill, Y., Eisner, A. and Osborn, L. "The Flight Application of a Pulsed Plasma Microthruster; The NOVA Satellite", AIAA Paper 82-1956, Nov. 1982.

${ }^{2}$ Vondra, R.J. and Thomassen, K.I., "Flight Qualified Pulsed Electric Thruster for Satellite Control", Journal of Spacecraft and Rockets, Vol. 11, No. 9, Sept. 1974, pp. 613-617.

${ }^{3}$ Meckel, N.J., Hoskins, W.A., Cassady, R.J., Myers, R.M., Oleson, S.R., McGuire, M.L., "Improved Pulsed Plasma Thruster System for Satellite Propulsion", AIAA 96-2735, July 1996.

4 Arrington, L.A., Haag, T.W., Pencil, E.J., Meckel, N.J., "A Performance Comparison of Pulsed Plasma Thruster Electrode Configurations", IEPC 97-127, August 24-28, 1997.

${ }^{5}$ Haag, T.W., "PPT Thrust Stand", AIAA Paper 952917, July 1995.

6 Benson, S.W., and Hoskins, W.A., "Fabrication, Qualification, and Integration of a PPT on the EO-1 Spacecraft", AIAA 99-2276, June 1999.

Table 1. Magnitude of Primary and Off-Axis Thrust for the BB PPT Fired Horizontally in the Test Chamber.

\begin{tabular}{|c|c|c|c|c|c|c|}
\hline & \multicolumn{2}{|c|}{ Z-Axis } & \multicolumn{2}{c|}{ Y-Axis } & \multicolumn{2}{c|}{ X-Axis } \\
\hline $\begin{array}{c}\text { Energy, } \\
\text { Joules }\end{array}$ & $\begin{array}{c}\text { Thrust, } \\
\mu \mathrm{N}\end{array}$ & $\begin{array}{c}\text { Impulse Bit, } \\
\mu \mathrm{N}-\mathrm{sec}\end{array}$ & $\begin{array}{c}\text { Thrust, } \\
\mu \mathrm{N}\end{array}$ & $\begin{array}{c}\text { Impulse Bit, } \\
\mu \mathrm{N}-\mathrm{sec}\end{array}$ & $\begin{array}{c}\text { Thrust, } \\
\mu \mathrm{N}\end{array}$ & $\begin{array}{c}\text { Impulse Bit, } \\
\mu \mathrm{N} \text {-sec }\end{array}$ \\
\hline 54 & 890 & 888 & 19 & 24 & 67 & 63 \\
\hline 43 & 710 & 710 & 15 & 16 & 57 & 58 \\
\hline 32 & 522 & 518 & 8 & 12 & 47 & 47 \\
\hline 21 & 303 & 301 & 2 & -- & 33 & 36 \\
\hline
\end{tabular}

Table 2. Thrust and Impulse Bit Angles from the Primary Axis for the BB PPT.

\begin{tabular}{|c|c|c|c|c|}
\hline & \multicolumn{2}{|c|}{ Y-Axis } & \multicolumn{2}{c|}{ X-Axis } \\
\hline $\begin{array}{c}\text { Energy, } \\
\text { Joules }\end{array}$ & $\begin{array}{c}\text { Thrust angle, } \\
\text { degrees }\end{array}$ & $\begin{array}{c}\text { Impulse bit } \\
\text { Angle, degrees }\end{array}$ & $\begin{array}{c}\text { Thrust angle, } \\
\text { degrees }\end{array}$ & $\begin{array}{c}\text { Impulse bit } \\
\text { Angle, degrees }\end{array}$ \\
\hline 54 & 1.2 & 1.5 & 4.3 & 4.5 \\
\hline 43 & 1.2 & 1.3 & 4.6 & 4.5 \\
\hline 32 & 0.9 & 1.3 & 5.1 & 5.2 \\
\hline 21 & 0.6 & -- & 6.2 & 6.8 \\
\hline
\end{tabular}


Table 3. Measurement Uncertainties and Variation in Thrust and Impulse Bit for the BB PPT, Single Point Maximum to Minimum Value Divided by the Averaged Primary Axis Component.

\begin{tabular}{|c|c|c|c|c|}
\hline & \multicolumn{2}{|c|}{ Uncertainties } & \multicolumn{2}{c|}{ Variation } \\
\hline $\begin{array}{c}\text { Energy, } \\
\mathrm{J}\end{array}$ & $\begin{array}{c}\text { Thrust } \\
\%\end{array}$ & $\begin{array}{c}\text { Impulse bit } \\
\%\end{array}$ & $\begin{array}{c}\text { Thrust } \\
\%\end{array}$ & $\begin{array}{c}\text { Impulse bit } \\
\%\end{array}$ \\
\hline 54 & 5.0 & 4.9 & 14 & 11 \\
\hline 43 & 3.0 & 2.7 & 7.3 & 11 \\
\hline 32 & 2.3 & 2.2 & 15 & 16 \\
\hline 21 & 2.0 & 3.5 & 16 & 27 \\
\hline
\end{tabular}

Table 4. Magnitude of the Off-Axis Performance in with PPT Fired Vertically in the Test Chamber and Final Primary Axis Performance for the BB PPT.

\begin{tabular}{|c|c|c|c|c|}
\hline & \multicolumn{2}{|c|}{$\mathrm{X}$ - Axis } & \multicolumn{2}{c|}{ Z-Axis } \\
\hline $\begin{array}{c}\text { Energy, } \\
\mathrm{J}\end{array}$ & $\begin{array}{c}\text { Thrust, } \\
\mu \mathrm{N}\end{array}$ & $\begin{array}{c}\text { Impulse bit, } \\
\mu \mathrm{N}-\mathrm{sec}\end{array}$ & $\begin{array}{c}\text { Thrust, } \\
\mu \mathrm{N}\end{array}$ & $\begin{array}{c}\text { Impulse bit, } \\
\mu \mathrm{N}-\mathrm{sec}\end{array}$ \\
\hline 54 & 55 & 63 & 922 & 937 \\
\hline 43 & 42 & 37 & 723 & 734 \\
\hline 32 & 31 & 34 & 515 & 519 \\
\hline 21 & 23 & 30 & 303 & 305 \\
\hline
\end{tabular}

Table 5. Magnitude of Primary Axis Thrust of the EO-1 PPT.

\begin{tabular}{|c|c|c|c|c|c|}
\hline \multicolumn{2}{|c|}{} & \multicolumn{2}{|c|}{ Side I } & \multicolumn{2}{c|}{ Side2 } \\
\hline $\begin{array}{c}\text { Charge } \\
\text { Time, ms }\end{array}$ & $\begin{array}{c}\text { Energy, } \\
\mathrm{J} \\
\text { (estm'd) }\end{array}$ & $\begin{array}{c}\text { Thrust, } \\
\mu \mathrm{N}\end{array}$ & $\begin{array}{c}\text { Impulse Bit, } \\
\mu \mathrm{N}-\mathrm{sec}\end{array}$ & $\begin{array}{c}\text { Thrust, } \\
\mu \mathrm{N}\end{array}$ & $\begin{array}{c}\text { Impulse Bit, } \\
\mu \mathrm{N}-\mathrm{sec}\end{array}$ \\
\hline 920 & 55.8 & 789 & 812 & 854 & 856 \\
\hline 720 & 43.2 & 602 & 602 & 652 & 663 \\
\hline 520 & 30.1 & 408 & 408 & 465 & 469 \\
\hline 320 & 18.7 & 225 & 226 & 268 & 266 \\
\hline 120 & 6.4 & 59 & 59 & 65 & 65 \\
\hline
\end{tabular}

Table 6. Magnitude of Off-axis Thrust of the EO-1 PPT.

\begin{tabular}{|c|c|c|c|c|c|c|c|c|}
\hline & \multicolumn{4}{|c|}{ X - Axis } & \multicolumn{4}{c|}{ Y - Axis } \\
\hline $\begin{array}{c}\text { Charge } \\
\text { Time, } \\
\mathrm{ms}\end{array}$ & $\begin{array}{c}\text { Thrust, } \\
\mu \mathrm{N}\end{array}$ & $\begin{array}{c}\text { Impulse } \\
\text { Bit, } \\
\mu \mathrm{N}-\mathrm{sec}\end{array}$ & $\begin{array}{c}\text { Thrust, } \\
\mu \mathrm{N}\end{array}$ & $\begin{array}{c}\text { Impulse } \\
\text { Bit, } \\
\mu \mathrm{N}-\mathrm{sec}\end{array}$ & $\begin{array}{c}\text { Thrust, } \\
\mu \mathrm{N}\end{array}$ & $\begin{array}{c}\text { Impulse } \\
\text { Bit, } \\
\mu \mathrm{N}-\mathrm{sec}\end{array}$ & $\begin{array}{c}\text { Thrust, } \\
\mu \mathrm{N}\end{array}$ & $\begin{array}{c}\text { Impulse } \\
\text { Bit, } \\
\mu \mathrm{N}-\mathrm{sec}\end{array}$ \\
\hline 920 & 45 & 41 & 44 & 43 & 4 & 11 & 9 & 12 \\
\hline 720 & 38 & 42 & 34 & 34 & -- & 8 & 5 & 14 \\
\hline 520 & 32 & 38 & 29 & 30 & -- & -- & 3 & 12 \\
\hline 320 & 21 & 20 & 16 & 16 & -- & - & -- & -- \\
\hline 120 & -- & -- & -- & -- & -- & -- & -- & -- \\
\hline
\end{tabular}


Table 7. Magnitude of Thrust and Impulse Bit Angles from Primary or Z - Axis to X - Axis of the EO- 1 PPT.

\begin{tabular}{|c|c|c|c|c|}
\hline & \multicolumn{2}{|c|}{ Side 1 } & \multicolumn{2}{c|}{ Side 2 } \\
\hline $\begin{array}{c}\text { Charge Time, } \\
\text { ms }\end{array}$ & $\begin{array}{c}\text { Thrust angle, } \\
\text { degrees }\end{array}$ & $\begin{array}{c}\text { Impulse bit } \\
\text { Angle, degrees }\end{array}$ & $\begin{array}{c}\text { Thrust angle, } \\
\text { degrees }\end{array}$ & $\begin{array}{c}\text { Impulse bit } \\
\text { Angle, degrees }\end{array}$ \\
\hline 920 & 3.3 & 2.9 & 2.9 & 2.9 \\
\hline 720 & 3.6 & 4.0 & 3.0 & 2.9 \\
\hline 520 & 4.5 & 5.3 & 3.6 & 3.7 \\
\hline 320 & 5.3 & 5.1 & 3.4 & 3.4 \\
\hline 120 & -- & -- & -- & -- \\
\hline
\end{tabular}

Table 8. Thrust and Impulse Bit Uncertainties for Primary or Z - Axis Measurements for the EO-1 PPT.

\begin{tabular}{|c|c|c|c|c|}
\hline & \multicolumn{2}{|c|}{ Side 1 } & \multicolumn{2}{c|}{ Side 2 } \\
\hline $\begin{array}{c}\text { Charge Time, } \\
\text { Ms }\end{array}$ & $\begin{array}{c}\text { Thrust, } \\
\%\end{array}$ & $\begin{array}{c}\text { Impulse bit, } \\
\%\end{array}$ & $\begin{array}{c}\text { Thrust, } \\
\%\end{array}$ & $\begin{array}{c}\text { Impulse bit, } \\
\%\end{array}$ \\
\hline 920 & 2.1 & 2.1 & 1.9 & 2.1 \\
\hline 720 & 2.4 & 2.3 & 2.0 & 2.3 \\
\hline 520 & 2.9 & 2.8 & 2.2 & 2.7 \\
\hline 320 & 3.3 & 4.4 & 2.1 & 4.0 \\
\hline 120 & 3.2 & 16 & 3.0 & 15 \\
\hline
\end{tabular}

Table 9. Variation in Thrust and Impulse Bit Measurements for the EO-1 PPT (single point maximum to minimum value divided by the average primary axis component).

\begin{tabular}{|c|c|c|c|c|}
\hline & \multicolumn{2}{|c|}{ Side 1 } & \multicolumn{2}{c|}{ Side 2 } \\
\hline $\begin{array}{c}\text { Charge Time, } \\
\text { ms }\end{array}$ & $\begin{array}{c}\text { Thrust, } \\
\%\end{array}$ & $\begin{array}{c}\text { Impulse bit, } \\
\%\end{array}$ & $\begin{array}{c}\text { Thrust, } \\
\%\end{array}$ & $\begin{array}{c}\text { Impulse bit, } \\
\%\end{array}$ \\
\hline 920 & 19 & 18 & 9.5 & 13 \\
\hline 720 & 22 & 11 & 11 & 15 \\
\hline 520 & 13 & 11 & 12 & 7.1 \\
\hline 320 & 22 & 38 & 17 & 17 \\
\hline 120 & 22 & 30 & 20 & 29 \\
\hline
\end{tabular}

Table 10. Magnitude of Primary Axis or Z - Axis Performance for EO-1 Thruster Post Life Test.

\begin{tabular}{|c|c|c|c|c|}
\hline & \multicolumn{2}{|c|}{ Side 1 } & \multicolumn{2}{c|}{ Side2 } \\
\hline Charge Time, ms & $\begin{array}{c}\text { Thrust, } \\
\mu \mathrm{N}\end{array}$ & $\begin{array}{c}\text { Impulse Bit, } \\
\mu \mathrm{N}-\mathrm{sec}\end{array}$ & $\begin{array}{c}\text { Thrust, } \\
\mu \mathrm{N}\end{array}$ & $\begin{array}{c}\text { ImpuIse Bit, } \\
\mu \mathrm{N}-\mathrm{sec}\end{array}$ \\
\hline 920 & 779 & 773 & 855 & 859 \\
\hline 720 & 555 & 558 & 643 & 657 \\
\hline 520 & 379 & 374 & 448 & 448 \\
\hline 320 & 222 & 218 & 249 & 251 \\
\hline 120 & --- & --- & -- & - \\
\hline
\end{tabular}




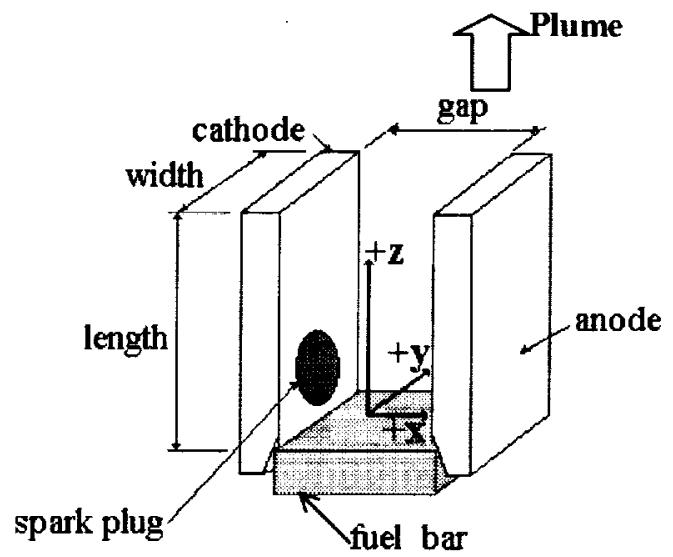

Figure 1. Isometric Sketch of Coordinate System for a PPT.

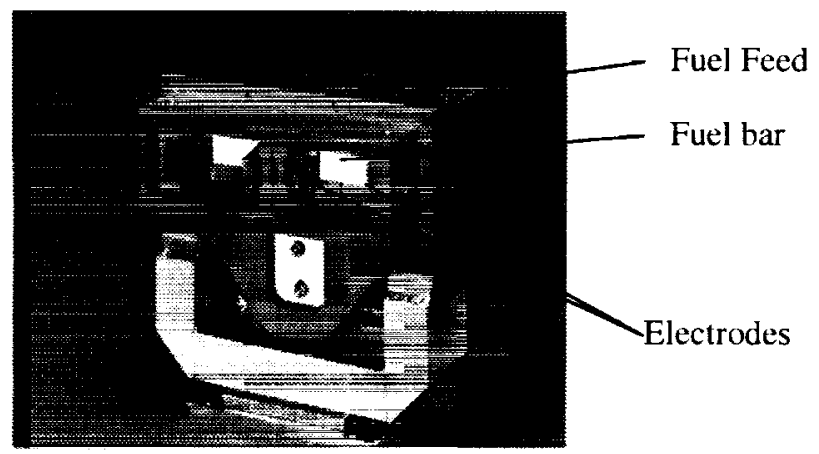

Figure 2. NASA/Primex Breadboard PPT.

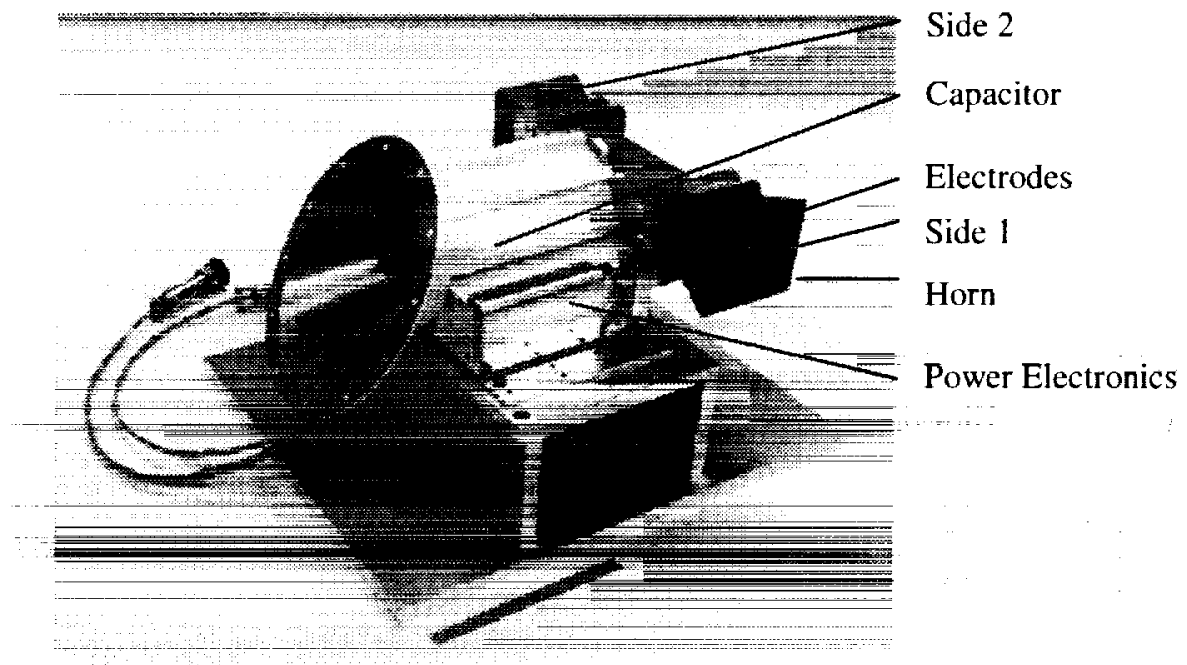

Figure 3. NASA/Primex EO-1 Protoflight Pulsed Plasma Thruster. 


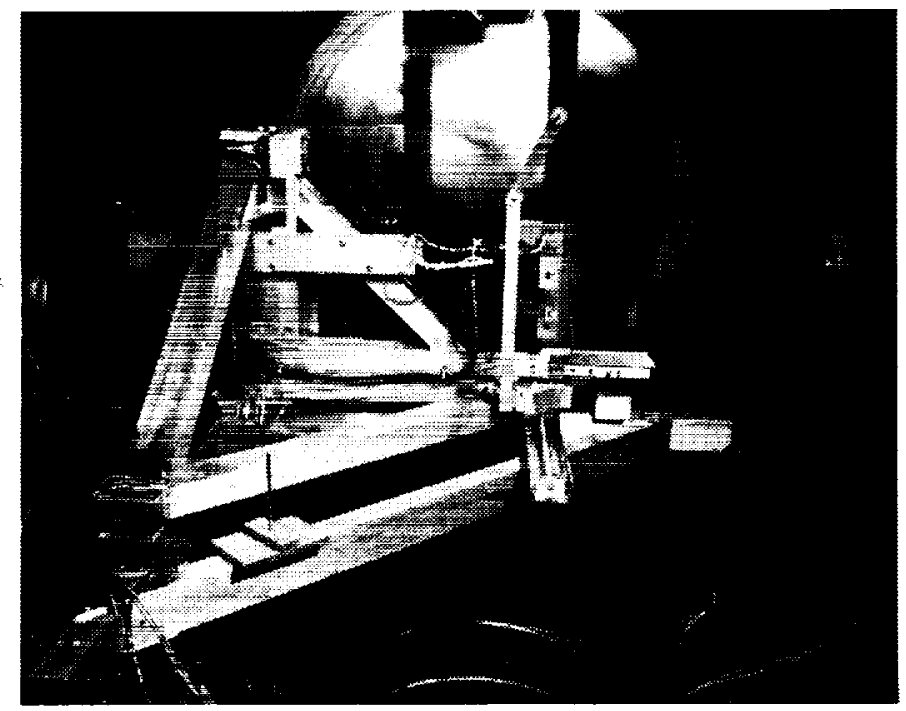

Figure 4. NASA/Primex Breadboard PPT on Thrust Stand to Measure Performance along the Z - axis.

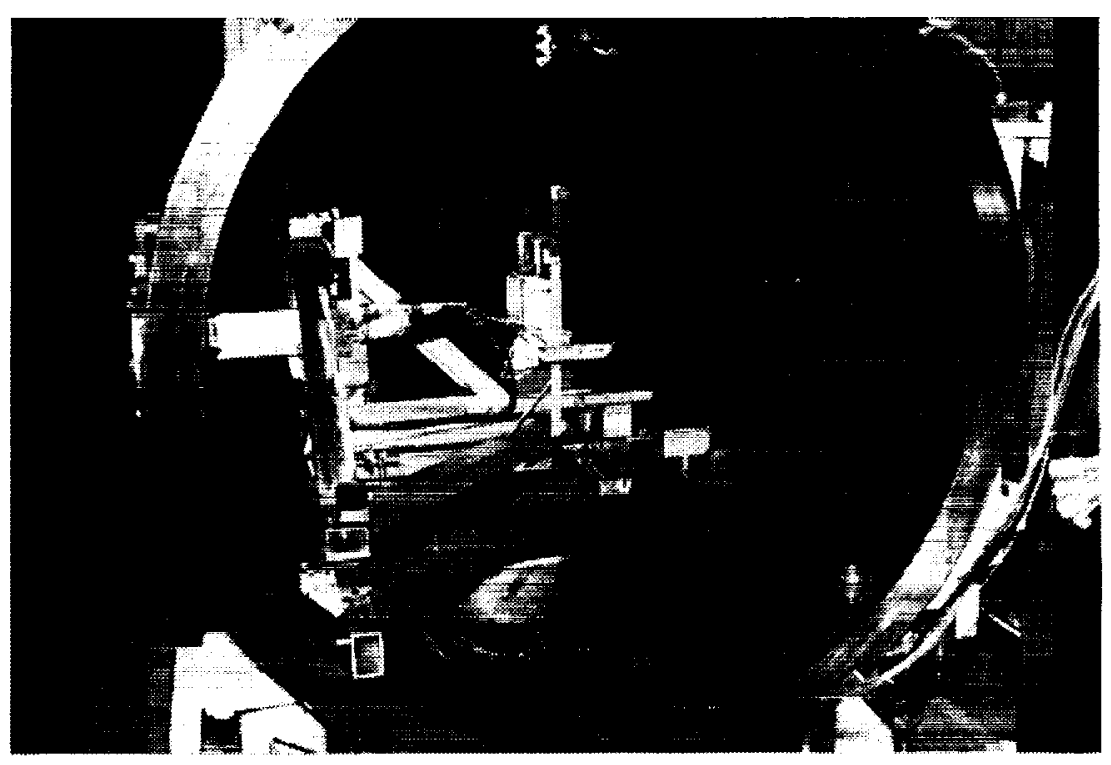

Figure 5. NASA/Primex EO-I Thruster Mounted on Thrust Stand for Primary or Z - Axis Performance Measurements of Side 2. 


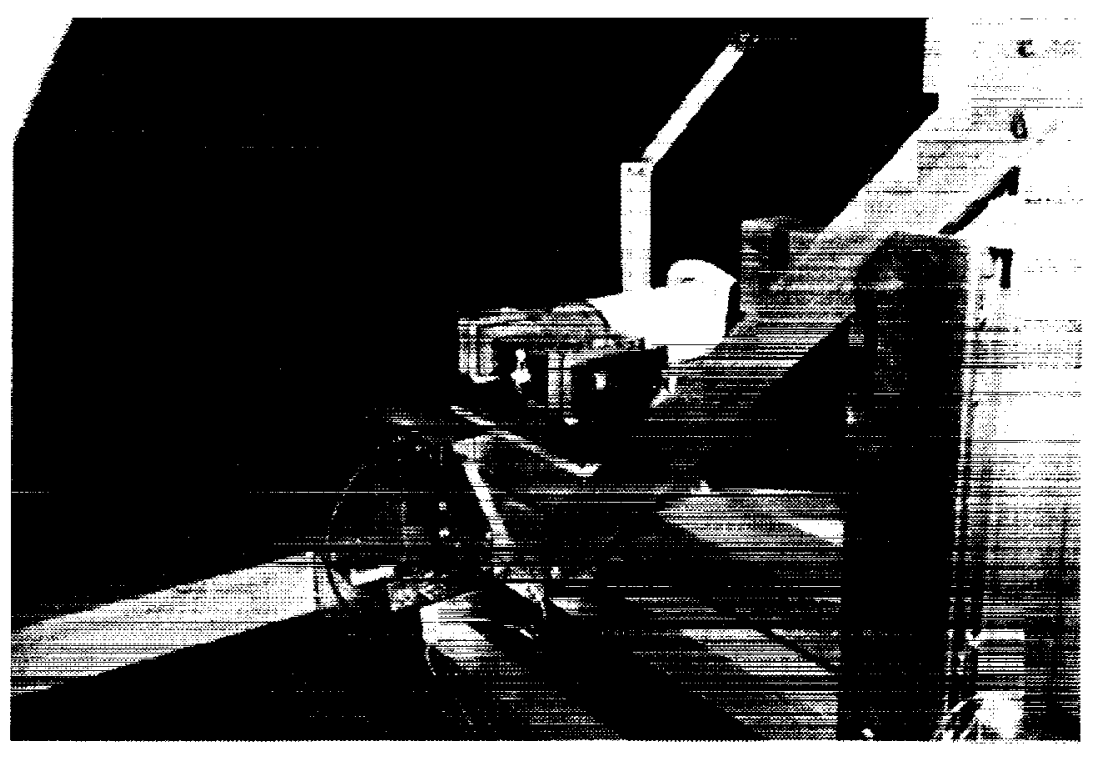

Figure 6. NASA/Primex EO-I Thruster Mounted on Thrust Stand for Off-axis Performance Measurements along the $\mathrm{X}$ - axis of Side 2 .

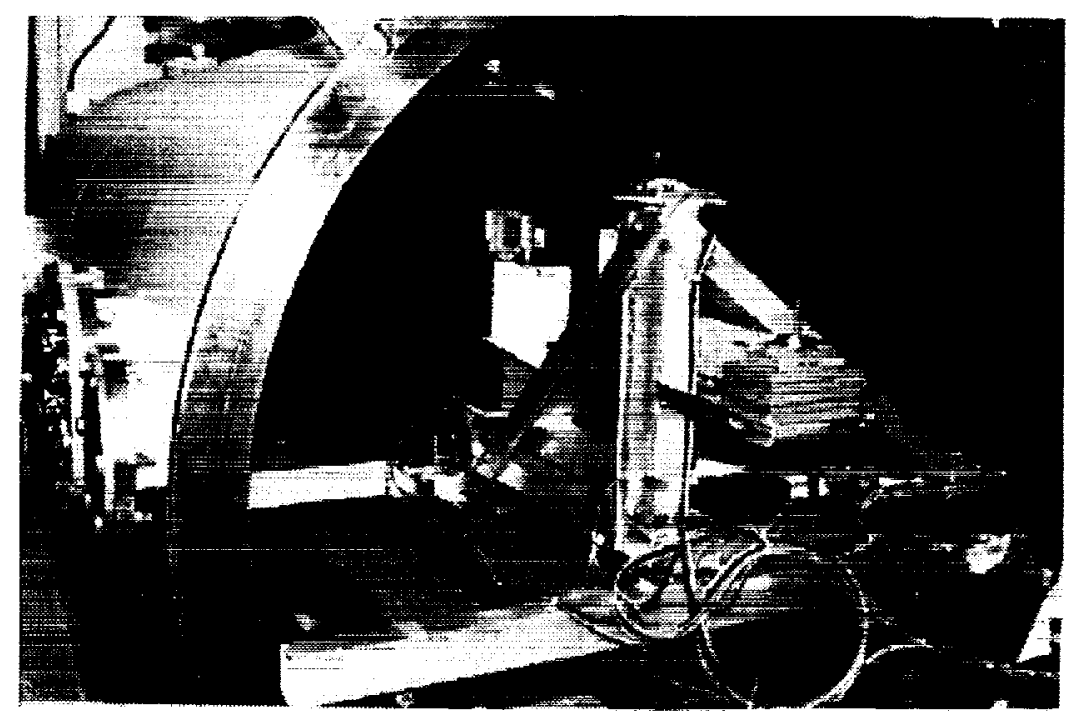

Figure 7. NASA/Primex EO-1 Thruster Mounted on Thrust Stand for Off-axis Performance Measurements along the $\mathrm{Y}$ - axis of Side 1 . 


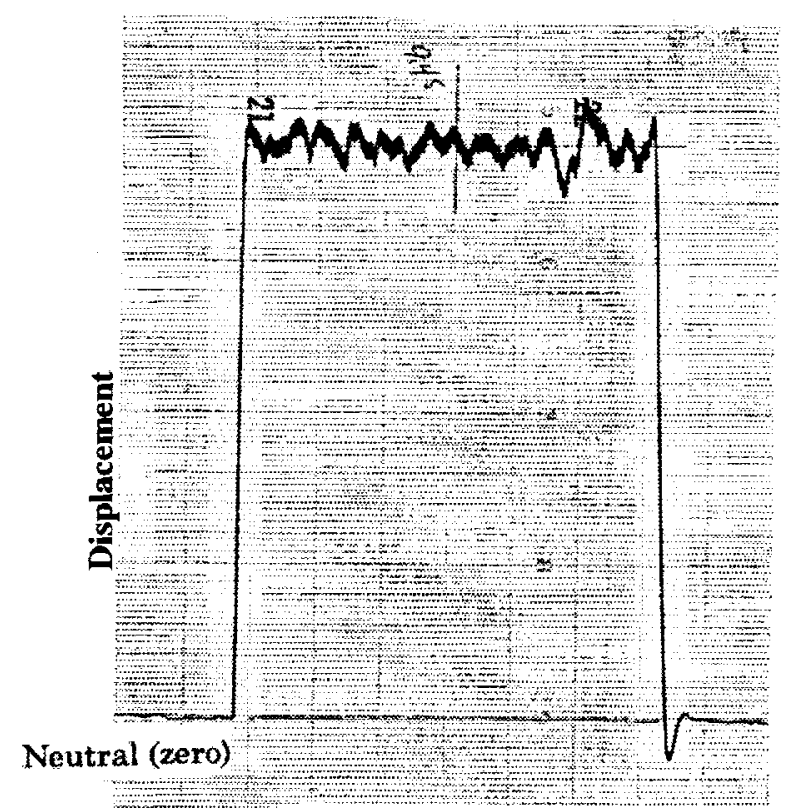

Time $+\gg \gg>$

Figure 8. Sample Thrust Stand Data from Strip Chart Recorder Used to Calculate Thrust Taken at $720 \mathrm{~ms}$ Charge Duration on Side 1 over a Period of 3 Minutes at a Pulse Rate of $1 \mathrm{~Hz}$.

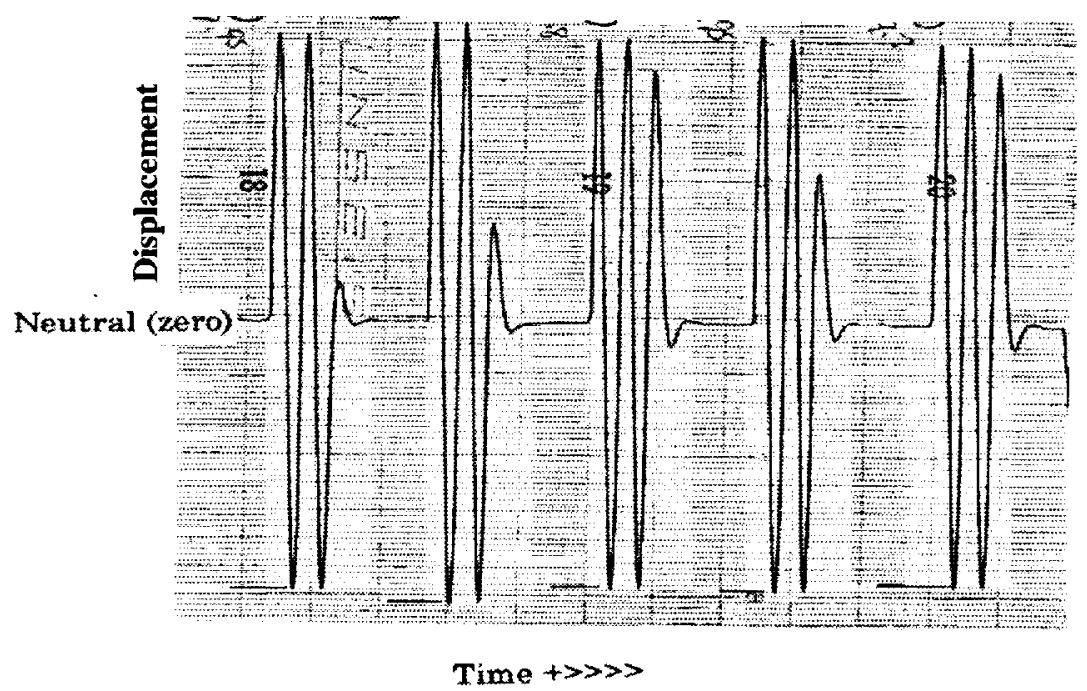

Figure 9. Sample Thrust Stand Data from Strip Chart Recorder (speed 2div/min) Used to Calculate Impulse Bit Taken at 720 ms Charge Duration on Side 1. 


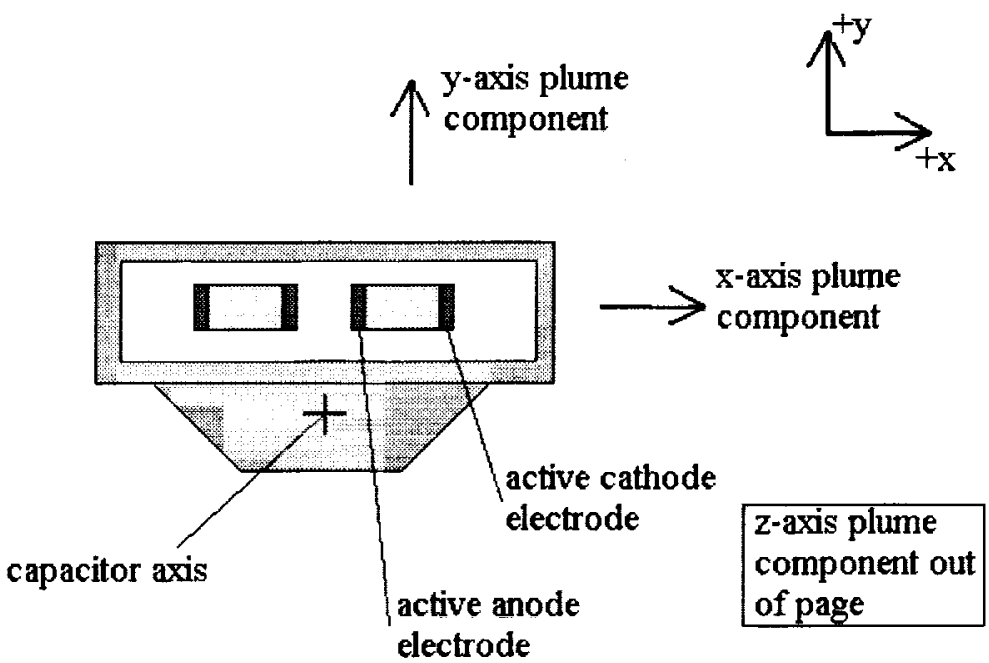

Figure 10. Direction of Plume Components for Breadboard PPT(not to scale).

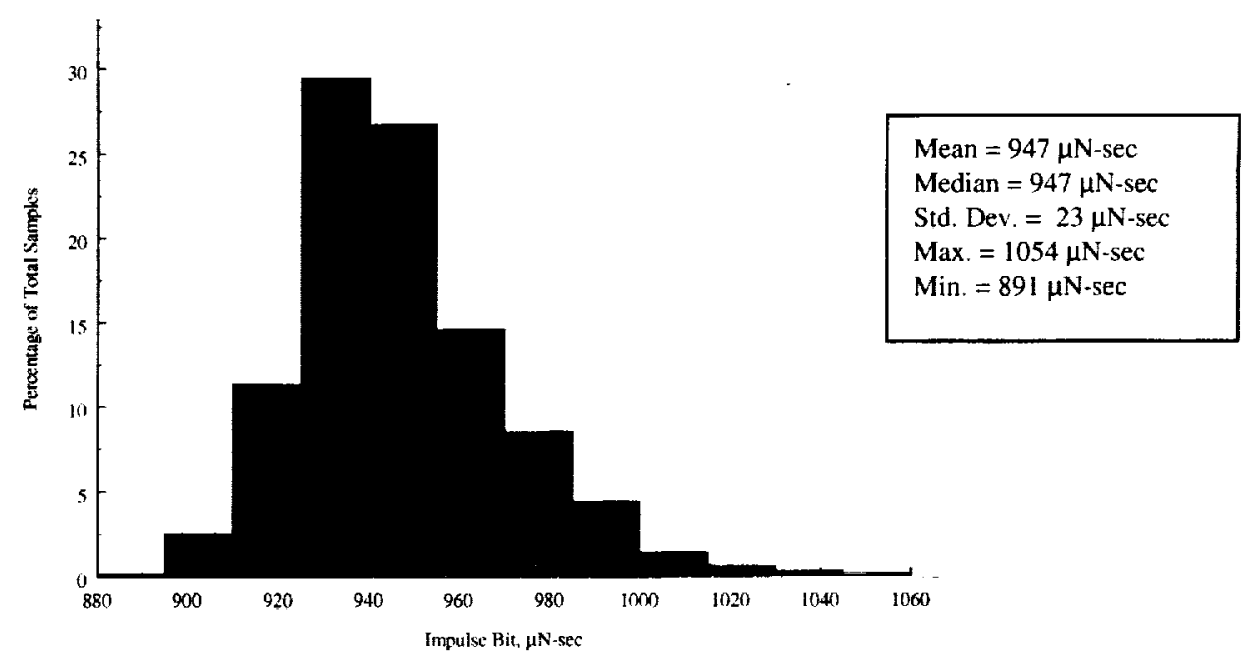

Figure 11. Distribution of 700 Pulse Impulse Bit Test at 54 Joules with the BB PPT. 


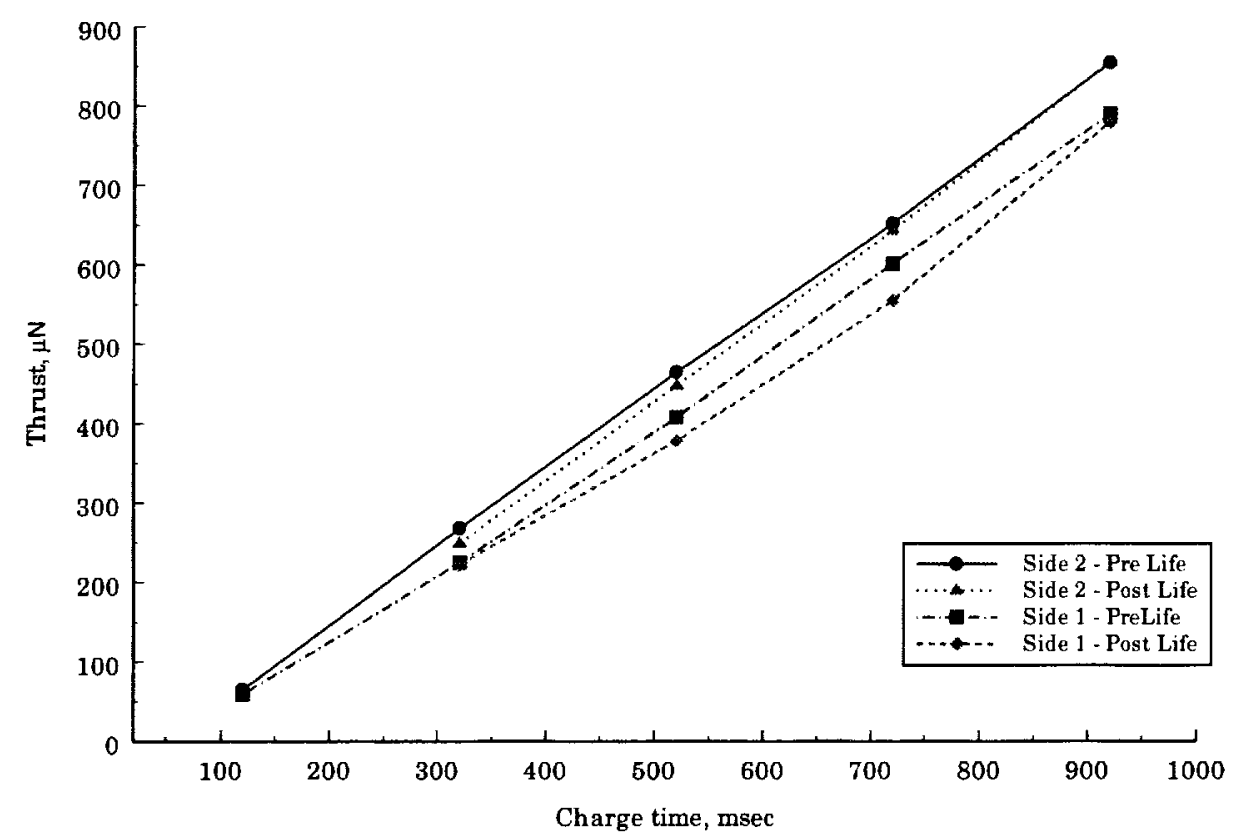

Figure 12. Pre and Post Life Thrust versus Charge Time for Both Sides of the EO-1 PPT Pulsing at $1 \mathrm{~Hz}$.

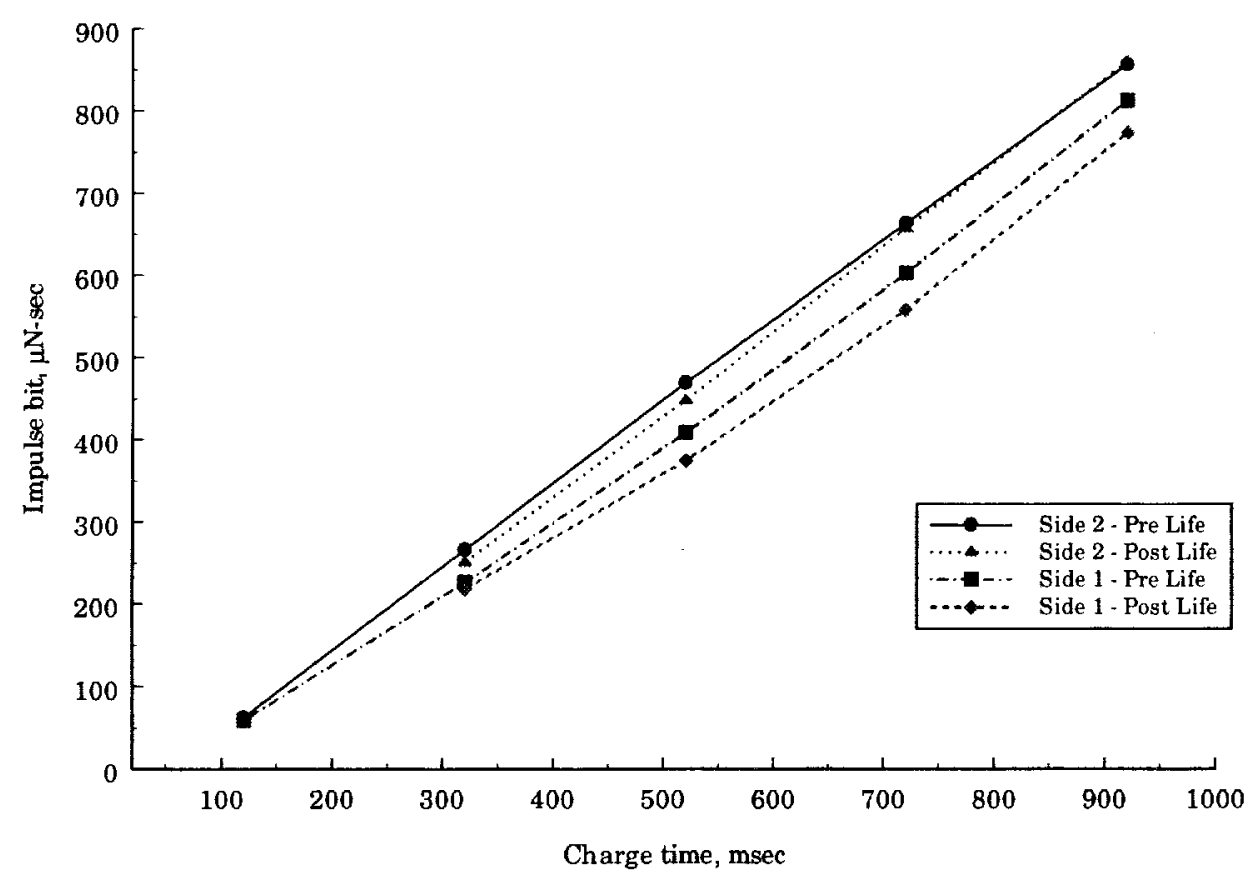

Figure 13. Pre and Post Life Impulse Bit versus Charge Time for Both Sides of the EO-1 PPT. 


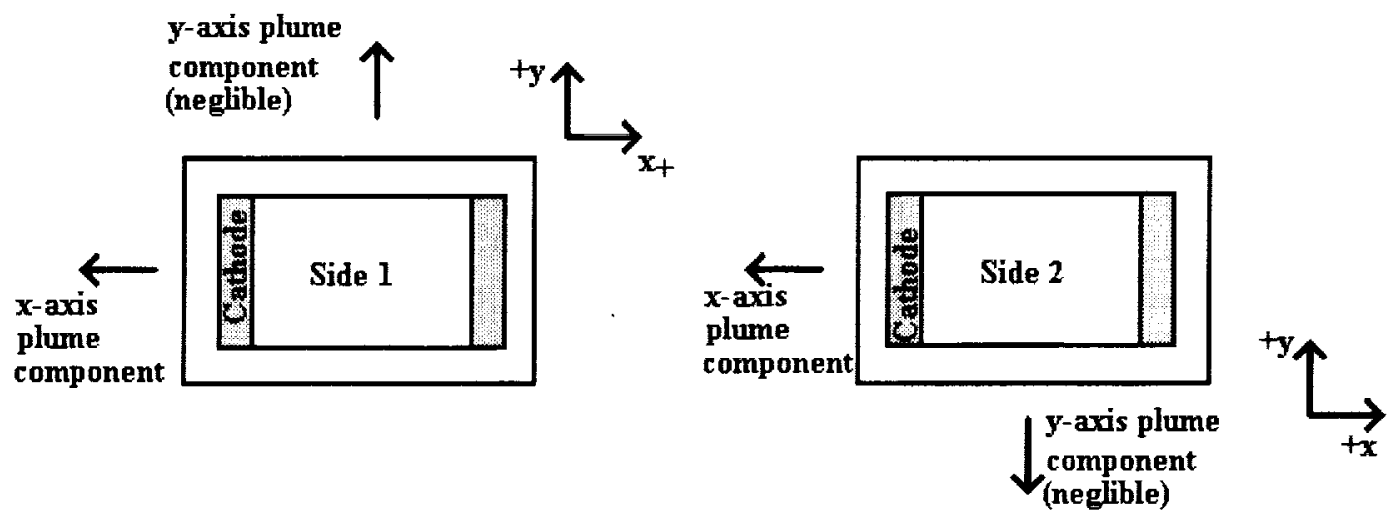

(end view of each side)

Main plume or $+z$ axis out of page

Figure 14. Direction of Plume for EO-1 PPT Off-axis Components(not to scale).

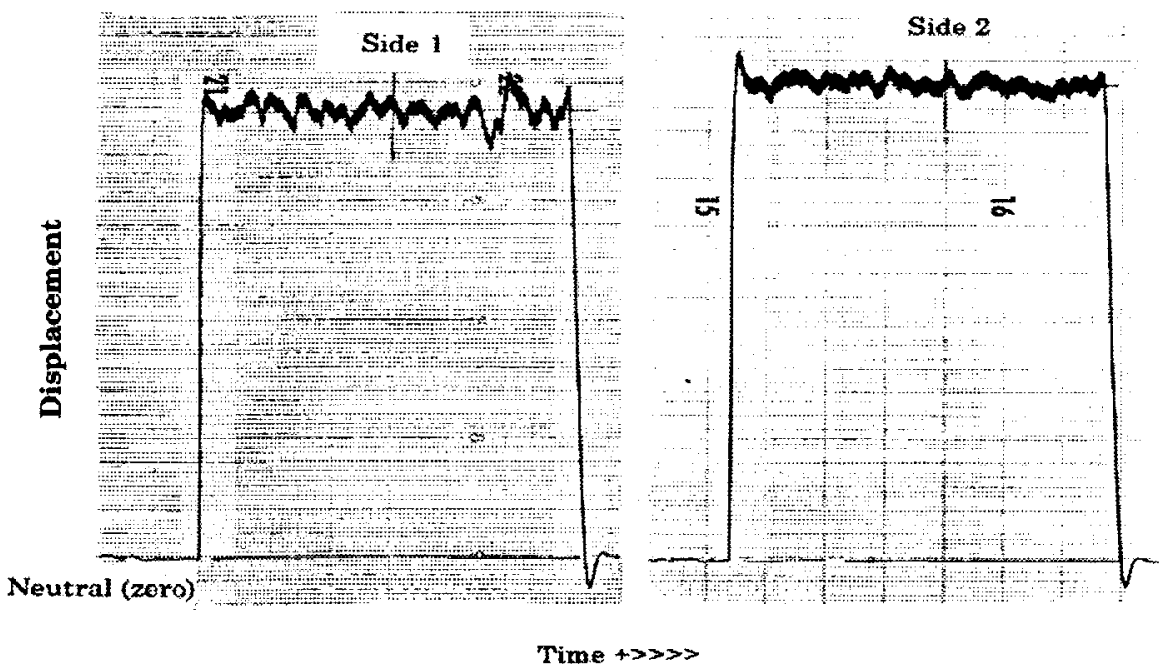

Figure 15. Sample Thrust Stand Data from Strip Chart Recorder (3min at $1 \mathrm{~Hz}$ ) Used to Calculate Thrust Taken at $720 \mathrm{~ms}$ Charge Duration on Side 1 and Side 2 of EO-1 PPT. 


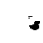


Public reporting burden for this collection of information is estimated to average 1 hour per response, including the time for reviewing instructions, searching existing data sources, gathering and maintaining the data needed, and completing and reviewing the collection of information. Send comments regarding this burden estimale or any other aspect of this collection of information, including suggestions for reducing this burden, to Washington Headquarters Services, Directorate for Information Operations and Reports, 1215 Jefferson Davis Highway. Suite 1204, Artington, VA 22202-4302, and to the Office of Management and Budget. Paperwork Reduction Project (0704-0188), Washington, DC 20503.

\begin{tabular}{|l|l|l|}
\hline 1. AGENCY USE ONLY (Leave blank) & 2. REPORT DATE & 3. REPORT TYPE AND DATES COVERED
\end{tabular}

\begin{tabular}{|l|c|c|} 
& September 1999 & \multicolumn{2}{|c}{ Technical Memorandum } \\
\hline 4. TITLE AND SUBTITLE & 5. FUNDING NUMBERS
\end{tabular}

Multi-Axis Thrust Measurements of the EO-1 Pulsed Plasma Thruster

6. AUTHOR(S)

WU-632-1B-1B-00

Lynn A. Arrington and Thomas W. Haag

7. PERFORMIING ORGANIZATION NAME(S) AND ADDRESS(ES)

National Aeronautics and Space Administration

John H. Glenn Research Center at Lewis Field

Cleveland, Ohio 44135-3191

8. PERFORMING ORGANIZATION

REPORT NUMBER

E-11830

9. SPONSORINGMONITORING AGENCY NAME(S) AND ADDRESS(ES)

National Aeronautics and Space Administration

Washington, DC 20546-0001

10. SPONSORING/MONITORING

AGENCY REPORT NUMBER

NASA TM-1999-209396

AIAA-99-2290

\section{SUPPLEMENTARY NOTES}

Prepared for the 35th Joint Propulsion Conference and Exhibit cosponsored by AIAA, ASME, SAE, and ASEE, Los Angeles, California, June 20-24, 1999. Lynn A. Arrington, Dynacs Engineering Company, Inc., Brook Park, Ohio, and Thomas W. Haag, NASA Glenn Research Center. Responsible person, Thomas W. Haag, organization code 5430, (216) $977-7423$.

Unclassified - Unlimited

Subject Categories: 18 and 20

Distribution: Nonstandard

This publication is available from the NASA Center for AeroSpace Information, (301) 621-0390.

\section{ABSTRACT (Maximum 200 words)}

Pulsed plasma thrusters are low thrust propulsive devices which have a high specific impulse at low power. A pulsed plasma thruster is currently scheduled to fly as an experiment on NASA's Earth Observing-1 satellite mission. The pulsed plasma thruster will be used to replace one of the reaction wheels. As part of the qualification testing of the thruster it is necessary to determine the nominal thrust as a function of charge energy. These data will be used to determine control algorithms. Testing was first completed on a breadboard pulsed plasma thruster to determine nominal or primary axis thrust and associated propellant mass consumption as a function of energy and then later to determine if any significant off-axis thrust component existed. On conclusion that there was a significant off-axis thrust component with the breadboard in the direction of the anode electrode, the test matrix was expanded on the flight hardware to include thrust measurements along all three orthogonal axes. Similar off-axis components were found with the flight unit.

14. SUBJECT TERMS

Pulsed plasma thruster; Thrust; Impulse bit; Multi-axis thrust measurements; Off-axis OF REPORT

Unclassified

18. SECURITY CLASSIFICATION
OF THIS PAGE
Unclassified

19. SECURITY CLASSIFICATION
OF ABSTRACT
Unclassified

